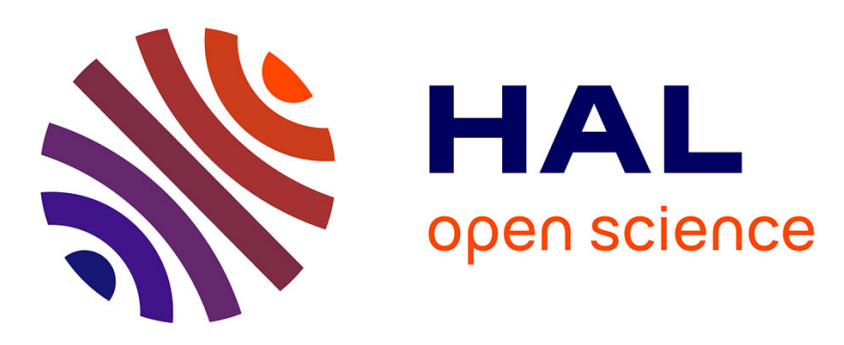

\title{
Relation between teachers' early expectations and students' later perceived competence in physical education classes: Autonomy-supportive climate as a moderator
}

David Trouilloud, Philippe Sarrazin, Pascal Bressoux, Julien Bois

\section{To cite this version:}

David Trouilloud, Philippe Sarrazin, Pascal Bressoux, Julien Bois. Relation between teachers' early expectations and students' later perceived competence in physical education classes: Autonomysupportive climate as a moderator. Journal of Educational Psychology, 2006, 98 (1), pp.75-86. hal00389006

\section{HAL Id: hal-00389006 https://hal.science/hal-00389006}

Submitted on 27 May 2009

HAL is a multi-disciplinary open access archive for the deposit and dissemination of scientific research documents, whether they are published or not. The documents may come from teaching and research institutions in France or abroad, or from public or private research centers.
L'archive ouverte pluridisciplinaire HAL, est destinée au dépôt et à la diffusion de documents scientifiques de niveau recherche, publiés ou non, émanant des établissements d'enseignement et de recherche français ou étrangers, des laboratoires publics ou privés. 
Running head: MODERATION OF TEACHER EXPECTATIONS EFFECTS

Relation between teachers' early expectations and students' later perceived competence in physical education classes: Autonomy-supportive climate as a moderator

David O. Trouilloud, Philippe G. Sarrazin

University J. Fourier of Grenoble

Pascal Bressoux

University P. Mendès-France of Grenoble

Julien Bois

University of Pau

Journal of Educational Psychology, 98, 75-86.

Correspondence concerning this article should be addressed to David Trouilloud or Philippe Sarrazin, Laboratoire Sport et Environnement Social EA 3742, UFRAPS Université Grenoble I, BP 53 - 38041 Grenoble Cedex 9 - France. E-mail: david.trouilloud@jf-grenoble.fr or philippe.sarrazin@ujf-grenoble.fr 


\begin{abstract}
The purpose of this study was to explore whether, in naturalistic physical education classes, the relation between teachers' early expectations and students' later perceived competence was moderated by the extent to which the motivational climate created by the teachers was autonomy supportive. Using a one year longitudinal design, data were obtained from 421 students and 22 teachers from 10 French junior high schools. Multilevel analyses revealed that (1) teachers' early expectations were related to students' later perceived competence, particularly when these expectations were positive, and (2) this relation was stronger when the classroom motivational climate was low in autonomy support. Implications for future research and educational practices are discussed.
\end{abstract}

Key Words: teacher expectations, self-fulfilling prophecy, perceived competence, moderation, multilevel analysis, self-determination theory, autonomy-supportive climate. 
Relation between teachers' early expectations and students' later perceived competence in physical education classes: Autonomy-supportive climate as a moderator

Most theoretical approaches of motivation and achievement, such as achievement goal (Nicholls, 1989), control (Skinner, 1995), expectancy-value (Eccles \& Wigfield, 2002), selfdetermination (Deci \& Ryan, 2002), and self-efficacy (Bandura, 1997) theories, consider perceived competence as one of the primary psychological predictors of motivational dynamic, well-being, and performance. Specifically, high academic perceived competence (or other similar constructs) ${ }^{1}$ has been found to be strongly related to positive achievement-oriented behaviors such as engagement, provided effort, persistence after failure, low anxiety, emotional stability, internal locus of control, intrinsic motivation, mastery goal orientation, and to academic achievement (see Bong \& Skaalvik, 2003, for a review). This is why, over the last 30 years, psychological and educational researchers have tried to identify factors that could influence students' perceived competence (Pajares \& Schunk, 2002). Most studies showed that children's perception of their own ability is mainly formed through experience with and interpretation of their environment (Bandura, 1997; Harter, 1999; Pintrich \& Schunk, 1996). In the educational context, one of the most influential sources of students' perceived competence is the evaluative and supportive feedback received from teachers (e.g., Stipek, 2002). The frequency and the characteristics of the information given by the teachers may strongly influence what students think they are capable of. On this point, several studies highlight the role played by teachers' expectations in determining how teachers will interact with (and perceive) their students (see Good \& Brophy, 2000, for a review). Teachers' expectations, by leading to differential treatment and evaluation, may be one environmental factor leading to the development of high or low perceived competence among students.

\section{Teacher Expectations Effects}

The role played by teachers' expectations on students' academic ability has been an important topic of educational research for almost 30 years. Today, there is no doubt that teachers' expectations can influence their behaviors toward students (Good \& Brophy, 2000; Harris \& 
Rosenthal, 1985), and thus students' self-perceptions, motivation, and achievement (e.g., Jussim, 1989; Pelletier \& Vallerand, 1996; Trouilloud, Sarrazin, Martinek, \& Guillet, 2002). This is the concept of teacher expectations effects (TEE; Good, 1987). TEE occur when the teacher expectations about a student affect teacher-student interactions in a manner that leads the student to fulfill the teacher expectations ${ }^{2}$. Naturalistic studies have repeatedly found support for the presence of TEE in classrooms (see Jussim \& Harber, 2005; Trouilloud \& Sarrazin, 2003, for reviews).

The shaping of students' perceived competence through the TEE process is now relatively well-documented. According to most socio-psychological models (e.g., Darley \& Fazio, 1980; Jussim, 1986; Miller \& Turnbull, 1986), one of the consequences of a perceiver holding an expectation is that this expectation may lead the target not only to behave consistently with the expectation, but to conclude that he/she is actually that type of person. Thus, if a teacher believes that a particular student is "low" in competence, this student, after numerous interactions with the teacher, may conclude that he or she is actually "low" in competence, and therefore have a low perceived competence. Indeed, teachers' early expectations for their students' ability had been shown to influence students' later self-concept of ability, in various contexts such as mathematics (e.g., Jussim, 1989; Parsons, Kaczala, \& Meece, 1982; Madon, et al., 2001), reading (e.g., Brattesani, Weinstein, \& Marshall, 1984) and physical education classes (Trouilloud et al., 2002). For example, Jussim (1989) showed that teachers' expectations of students' performance in October significantly predicted changes in students' self-concept of math ability in the spring, even after controlling for students' previous achievement and perceived ability. Moreover, students' perceived competence seems to be one important mediator of TEE on students' achievement (Jussim, 1986); that is, the influence of teachers' expectations on students' perceived competence may impact students' achievement (Trouilloud et al., 2002).

Moderators of TEE

Nevertheless, findings from numerous studies suggest that the influence of teachers' expectations tend to be small. Under naturalistic conditions, and after controlling for relevant 
background variables, TEE are of about .1 to .3 (in terms of standardized regression coefficients) on students' self-perceptions and achievement (see Jussim et al., 1998, for a review). Brophy (1983) assumed that teachers' expectations account on average for 5 to $10 \%$ of the variance in students' outcomes in a single year, a finding that can be described as significant but modest. This does not mean that TEE are never powerful. Effect sizes found in most prior studies (e.g., Jussim, 1989) are average, and thus may mask important variability across classrooms, teachers and students.

Actually, TEE must be considered as a probabilistic (i.e., non systematic) phenomenon (Babad, 1993). For a self-fulfilling prophecy to occur, teachers must have differential expectations for their students, they must communicate these expectations through their behavior toward students, students must react in specific ways to such differential treatment, and so on. Thus, because many conditions have to be combined to generate the confirmation of teachers' expectations, this process may not take place in every classroom, for every student, and for every teacher. For this reason, recent research abandoned the search for the "existence" of TEE and focused on identifying when, where and for whom this phenomenon is more likely to occur (Jussim et al., 1998; Weinstein \& McKown, 1998). Nevertheless, although the existence of moderators in interpersonal expectations effects has been argued theoretically (Darley \& Fazio, 1980; Jussim, 1986) and empirically supported in experimental studies (see Snyder \& Stukas, 1999, for a review), little is known about moderators of naturally occurring TEE. Only a few studies have explored whether certain student, teacher, or classroom characteristics might increase (or decrease) the magnitude of TEE. In the following sections, we briefly review the empirical evidence on this topic.

Students' moderation. Students may not be equally susceptible to TEE. Some students are more sensitive than others to teachers' expectations-related behaviors (such as voice tones and other communication cues), so that they may interpret teachers' communication of expectations more often and more accurately, and thus are potentially more affected by them. On this point, research has explored demographic differences as well as past scholarship differences in students' susceptibility to TEE. Specifically, TEE appeared to be stronger among students who are either 
African-American (Jussim, Eccles, \& Madon, 1996; McKown \& Weinstein, 2002) or from lower socio-economic backgrounds (Jussim et al., 1996), and among students who are low achievers (Madon, Jussim, \& Eccles, 1997) and with low or unclear self-concept (Brattesani et al., 1984). Thus, it seems that students in vulnerable or stigmatized groups (e.g., students from low socioeconomic backgrounds of from ethnic minorities) and students with poor past scholarship (e.g., poor previous achievement and low self-concept) are more likely to be influenced by teachers' expectations than are others students.

Teachers' moderation. Although all teachers must have differential expectations for their students, not all teachers demonstrate expectations effects in their classrooms. There may be differences among teachers in predisposition to expectations effects. Some researchers have tried to identify the characteristics of teachers who are prone to generate this process. Results showed that teachers' (1) propensity to treat high and low achievers differently (Brattesani et al., 1984; Kuklinski \& Weinstein, 2001), (2) sense of control (Cooper \& Good, 1983), and (3) susceptibility to biasing information about students (Babad, Inbar, \& Rosenthal, 1982) seem to be important moderators of TEE. For example, studies done in reading classes (e.g., Kuklinski \& Weinstein, 2001) showed that teachers' expectations had more impact on students' end-of-year reading scores in classrooms where students perceived higher levels of differential teacher behavior. Students who perceived salient differences in teacher treatment of high vs. low achievers were more accurate in their perceptions of teacher expectations-related behaviors (Weinstein, Marshall, Botkin, \& Sharp, 1987), and were consequently more likely to confirm teachers' earlier expectations. This pattern of results suggests that when teachers' expectations are expressed in salient differences in students' treatment, conditions are ripe for stronger effects.

Contextual moderation. Situational or contextual factors may also influence students' susceptibility to teachers' expectations. Specifically, students seem more vulnerable to TEE in within-classroom ability grouping compared to between-classroom ability grouping classes (Eder, 1981; Smith, Jussim, \& Eccles, 1998), when they are negotiating transitions (e.g., start of 
kindergarten or middle school) (Raudenbush, 1984), and in classrooms with large number of students and few resources (Finn, 1972; Jussim et al., 1998).

\section{This Study}

As seen before, certain individual or contextual characteristics might significantly increase (or decrease) the magnitude of TEE. Relatively little research, nevertheless, has been conducted on moderators of TEE in naturalistic contexts. Because TEE may have major consequences on students' (perceived or actual) ability, it seems important to increase our knowledge about the conditions under which such effects are maximized, minimized, or even changed (Weinstein \& McKown, 1998). Existing studies leave several important issues unexplored, notably concerning contextual moderators of TEE. Indeed, although some works (Brattesani et al., 1984; Kuklinski \& Weinstein, 2001) indicate that some classroom environment characteristics may moderate TEE, many questions remain. Largely ignored is the potential role played by factors such as classroom motivational climate. Whereas the motivational climate created by a teacher is considered by educational and psychological researchers (e.g., Ames, 1992) as an important factor in students' development, no study, to our knowledge, has explored whether and how this factor may operate in TEE process. Understanding the role of motivational climate will help identify when and where teachers' expectations may strongly impact students' outcomes.

\section{Motivational climate as a moderator: A self-determination theory perspective}

A great deal of research in the last three decades has highlighted how various aspects of the classroom motivational climate may affect students' educational outcomes such as perceived competence, motivation and performance (e.g., Patrick, Anderman, \& Ryan, 2002; Stipek, 2002; Urdan, 2001). Specifically, the way students perceive and interpret the motivational climate established by their teacher can moderate the effects of external events on student outcomes (Deci, Vallerand, Pelletier, \& Ryan, 1991). Applying this idea to the TEE paradigm, one may think that the effects of social factors such as teachers' expectations on students' outcomes might be different, depending on the motivational climate in which teachers express them to students. Good and 
Brophy (2000) suggested that the potential for TEE is greatest in classrooms where teachers feature uniform rather than multiple goals, a narrow rather than a broad range of activity structures, normreferenced achievement standards, a competitive atmosphere, public performance evaluation, and an emphasis on achievement rather than effort. Although the moderator role played by motivational climate on the TEE process has been theoretically expressed (e.g., Good \& Brophy, 2000; Weinstein \& McKown, 1998), no prior naturalistic study, however, has empirically explored this assumption. The main purpose of this study was thus to evaluate whether TEE on students' perceived competence vary differently depending on the nature of motivational climate at the classroom level.

According to self-determination theory (Deci \& Ryan, 2002), one characteristic of the motivational climate may particularly influence students' development: the degree to which this climate is oriented toward autonomy support. An autonomy-supportive climate can be characterized as a motivational style including behaviors such as offering choices, encouraging independent problem solving, involving students in the decision process, and minimizing the use of pressure (e.g., Reeve, Bolt, \& Cai, 1999; see Reeve, 2002, for a detailed description of autonomy-supportive behaviors). Several studies suggest that environments and classrooms practices that are perceived by students as autonomy-supportive may enhance students' internal locus of causality, intrinsic motivation and self-determination (see Deci et al., 1991; Reeve, 2002, for reviews). Conversely, social contexts that are controlling (e.g., using rewards, directives, threats, evaluations, and pressuring students toward a particular outcome) undermine these dimensions. Consequently, because an autonomy-supportive climate generally influences students' level of self-determination, this particular contextual variable may affect students' susceptibility to social influence such as teachers' expectations.

Hypotheses

Teachers' expectations effects on students' perceived competence 
In agreement with the self-fulfilling prophecy process (Jussim, 1986; Snyder \& Stukas, 1999), we predicted that teachers' expectations early in the year would impact students' perceived competence later during that year. As in prior naturalistic studies (e.g., Jussim, 1989; Kuklinski \& Weinstein, 2001; Trouilloud et al., 2002), evidence for TEE is operationalized as the extent to which teachers' early expectations predict students' future outcomes (e.g., perceived competence), beyond what is predicted by students' relevant background characteristics.

Some researchers (e.g., Brophy \& Good, 1974; Eccles \& Wigfield, 1985) speculated that this relation between teachers' expectations and students' perceived competence may not be linear ; that is, TEE may vary depending on the valence (positive vs. negative) of teachers' expectations. Specifically, they anticipated that negative expectations may be more damaging than positive expectations are helpful. Very few studies have concretely explored this topic in a naturalistic education setting (for a review, see Jussim \& Harber, 2005). Moreover, the empirical evidence dealing with this issue has yielded equivocal findings. Actually, two studies (Babad et al., 1982; Sutherland \& Goldschmid, 1974) suggest that, under naturalistic conditions, teachers' expectations lead to more powerful self-fulfilling prophecies when expectations are negative than when they are positive. Conversely, one study (Madon et al., 1997) showed that positive teachers' expectations may be more powerful than negative ones. This inconsistency in findings highlights the need for additional investigation into the differential power of high versus low teachers' expectations. Autonomy-supportive climate as moderator of TEE

Because an autonomy-supportive environment enhances self-determination (see Deci \& Ryan, 2002), students evolving within this climate will be less susceptible to conform to social factors such as teachers' expectations. Moreover, an autonomy-supportive teacher may be less prone to demonstrate cues about his/her expectations (i.e., adopt expectations-related behaviors) toward his/her students. For these reasons, one may hypothesize that TEE tend to be relatively weak in an autonomy-supportive climate.

Conversely, because a non autonomy-supportive environment reduces self-determination, 
students within this climate would be more likely to adopt, internalize and conform to teachers' expectations. Moreover, a controlling teacher would be more prone to adopt rigid and strong expectations-related behaviors. On this point, several researchers (e.g., Cooper, 1979; Jussim et al., 1998) suggest that the need to control others may moderate TEE. Experimental studies have shown that persons with a greater "desire for control" and "need to influence" others' behaviors (which included dogmatism-related components such as influence ability, dominance, cognitive rigidity) are more likely to produce expectations effects (see Cooper \& Hazelrigg, 1988; Harris, 1989; Hazelrigg, Cooper, \& Strathman, 1991, for meta-analysis). This pattern of results led us to think that, in a naturalistic educational context, the more teachers attempt to control students, the more likely it is that their expectations will be self-fulfilling. Because they think and act in terms of shaping students' behaviors rather than "accommodating" to them, non autonomy-supportive teachers are most likely to produce TEE. Thus, we hypothesized that the degree to which motivational climate is autonomy-supportive will moderate the relation between teachers' early expectations and students' later perceived competence, such that this relation will be stronger in classrooms with low (vs. high) level of an autonomy-supportive climate.

\section{Method}

Sample

Participants in this study were 421 students ( 191 boys and 230 girls; $M$ age $=13.42$ years, $S D=1.73$ ) and their 22 physical education teachers in 10 French high schools. Students were in Grades $7(n=96), 8(n=88), 9(n=77), 10(n=79)$ and $11(n=81)$. They were largely white $(85 \%)$ and heterogeneous in socio-economic status. Teachers ( 7 men and 15 women) had teaching experience ranging from 1 to 30 years $(M=14.57$ years, $S D=5.73)$.

\section{Procedure}

This longitudinal study was conducted over one school year in physical education classes. The procedure used can be described in three steps. (1) During the first month of the school year, students responded to a questionnaire assessing their perceived competence in physical education. 
During the same month, teachers were asked to evaluate their expectations for each student's ability in physical education settings. (2) In the middle of the school year, students completed a questionnaire assessing their perception of the autonomy-supportive climate instituted by their physical education teacher. (3) Finally, during the last month of the school year, students' perceived competence was again assessed.

\section{Measures}

Teacher expectations of students' competence. The "Teacher Expectations Scale" (e.g., Jussim \& Eccles, 1992), was used to assess teachers' expectations about students' performance (i.e., “According to you, how good will this student be in physical education ?") and talent (i.e., "Does this student have a natural talent which will enable him/her to succeed in physical education ?"). Teachers rated items on a seven-point scale ranging from 1 (very bad) to 7 (very good). As these two items were strongly correlated $(r=.85)$, they were averaged to constitute one single dimension.

Student perceived competence. Perceived competence can be defined as the individual's perception of her/his current competence in an achievement context (Wigfield \& Eccles, 2000). To assess perceived ability in PE settings, a four-item questionnaire similar to the one developed by Nicholls and colleagues (Duda \& Nicholls, 1992; Nicholls, Cheung, Lauer, \& Patashnick, 1989), was used (e.g., "When you're in physical education setting, you consider yourself ..."). Responses were indicated on seven-point scale anchored by "very bad" (1) and "very good" (7). In previous research conducted on teenagers, this questionnaire had shown good construct validity, internal consistency, and predictive validity (e.g., Sarrazin, Roberts, Cury, Biddle, \& Famose, 2002). In this study, this scale possessed adequate internal consistency at the beginning and at the end of the year ( $\alpha=.75$ and .77 , respectively). The mean of the responses was calculated and considered as an indication of student perceived competence in physical education.

Perceived autonomy-supportive climate. Because it is students' perceptions (rather than objective measures) that are presumed to play the more important role in teachers' expectations process (Weinstein \& McKown, 1998), this study focused on students' perceptions of their 
classroom motivational climate, which have the advantage of reflecting the views of the ultimate recipients of teacher behaviors. Students' perceptions of the autonomy-supportive climate were assessed using a French version of the Learning Climate Questionnaire (see Black \& Deci, 2000) adapted for educational settings (e.g., I feel that my teacher provides students choices and options; $\alpha=.75$ ). Answers to the four items were assessed on a seven-point scale anchored by the end points "never" (1) to "always" (7).

Because aggregate measures of perceived climate yield a more comprehensive assessment of the perceived classroom environment than do individual factors (Church, Elliot, \& Gable, 2001; De Jong \& Westerhof, 2001), the mean of students' individual perceptions of the autonomy-supportive nature of the climate was calculated in each classroom. This index was used as a contextual variable describing the motivational climate at the classroom level. A necessary precondition for aggregation is a confirmation that there is within-class agreement with regard to the aggregated construct (Cohen, Doveh, \& Eick, 2001). To test this condition, an inter-rater agreement coefficient ( $R w g$ ) was calculated for each class (see James, Demaree, \& Wolf, 1993). In this study, inter-rater agreement corresponded to the level of agreement within a classroom about the autonomysupportive nature of the climate established by the teacher. Classroom autonomy-supportive climate exhibited a satisfying degree of inter-rater agreement $(R w g=.65$ to .80$)$, suggesting that students' perceptions were shared within classroom. These results suggest that it was suitable to aggregate the individual autonomy-supportive scores to the classroom level.

\section{Data Analyses}

Because the nesting of students within classrooms raised the possibility of dependencies in the data, hierarchical linear modeling (Bryk \& Raudenbush, 1992) - also called multilevel modeling - was chosen to perform our analysis. Most prior studies of TEE ignore class membership and between-classroom effects, and perform the analysis by combining $\mathrm{K}$ teachers and $\mathrm{N}$ students into a single and undifferentiated group. Such a procedure risks overlooking the importance of classroom effects, and may also render invalid many of the traditional statistical analysis techniques used for 
studying TEE. Actually, the hierarchically organized structure of the data, with students at level 1 and classrooms at level 2 , has several implications that are not properly taken into account by ordinary least squares (OLS) models (see Kenny, Kashy, \& Bolger, 1998).

Firstly, OLS models do not separate the different levels of analysis. Therefore, using OLS models, the data have to be aggregated at the highest level of the hierarchy, or they have to be disaggregated at the lowest level. In the first case, this can lead to the aggregation bias (Robinson, 1950) and in the second case, the number of units of the higher level variables is considerably inflated, leading to biased underestimated standard errors and inflating the risk of type I errors.

Secondly, students in the same classrooms are more alike than students from different classrooms $^{3}$. This causes non-independence in the residuals (i.e., intra-class correlation) leading again to biased underestimated standard errors. This is the case of OLS estimates since a strong assumption of OLS models is the independence of residuals.

Thirdly, classrooms in this study are a random sample of a population of classrooms and their effects have to be treated as random rather fixed. This means that we are interested in estimating variances rather than means, and that we have to partial out "true variance" from sampling variation. Because OLS models consider every effect as fixed, these effects are usually overestimated since sampling variation is not taken into account.

Finally, this study is specifically interested in a cross-level interaction, that is how the relation between teachers' expectations and students' perceived competence (i.e., a level-1 relation) varies as a function of classroom motivational climate (i.e., a level-2 variable). Such interactions are called cross-level interactions because they involve units at two levels of the nested hierarchy. Here again, because OLS models consider all variables as single-level ones, they do not take into account the different levels of analysis and do not allow to a proper estimation of cross-level interactions.

For the reasons mentioned above, hierarchical linear models were preferred since they have been specifically conceived in order to take into account hierarchically structured data. Multilevel analyses were performed using MLwin software version 2.1b (Rasbah et al., 2000). The first step 
was to use a fully unconditional two-level hierarchical model to partition the variance of students' end-of-year perceived competence into between-class and within-class components. This model is "unconditional" because the variance components are not predicted by any variable. Variances estimates produced by the unconditional model are used to calculate the intra-class correlation (ICC), an index of the proportion of total variance in the dependent variable (i.e., students' perceived competence) attributable to classroom membership. Results indicated the ICC to be .11 (see Table 2), meaning that $11 \%$ of the variance of students' perceived competence was between classes. This non-zero ICC suggests substantial dependence in the data across students' perceived competence and provides justification for using hierarchical models to answer our research questions.

Thus, the multilevel analyses were extended. The goal was to determine whether (1) teachers' early expectations predicted students' later perceived competence after controlling for students' background characteristics and (2) classroom autonomy-supportive climate could explain variation in this relation. Hypotheses were tested by constructing a series of hierarchical linear models. First, a base model was assessed (see Table 2), assuming that students' backgrounds characteristics (i.e., early perceived competence, gender, and age) and teachers' early expectations predicted students' later perceived competence. A quadratic term (created by squaring the teacher expectations variable) was then included in the model (see model 1; Table 2) to test the assumption that the relation between teachers' expectations and students' perceived competence is not linear such that the magnitude of teachers' expectations effects on students' perceived competence would depend on the level of such expectations (high vs. low).

Next, another model explored our contextual moderation hypothesis (i.e., hypothesis of interaction between teachers' expectations and classroom autonomy-supportive climate). For this, four variables were added to the base model: two product terms (created by multiplying the classroom autonomy-supportive climate variable with the two teacher expectations variables), and the autonomy-supportive climate scores at both classroom and individual level ${ }^{4}$ (see model 2, Table 
2). The hypothesis that classroom autonomy-supportive climate moderated TEE could be confirmed if the product terms significantly predict students' later perceived competence. In order to gain an appreciation of the magnitude of the effect, the standardized coefficient for high and low values of the moderator was calculated. This facilitates comparison of our findings with those reported in the literature.

\section{Results}

Descriptive statistics and intercorrelations among variables are reported in Table 1.

The results of this study are presented in two sections: (a) the relation between teachers' early expectations and students' later perceived competence and (b) the moderating role of classroom autonomy-supportive climate.

\section{Relation between teachers' early expectations and students' later perceived competence}

The base model was tested to evaluate whether teachers' early expectations predicted students' later perceived competence beyond what is predicted by students' background characteristics. This base model (see Table 2) included the higher order clustering variable of classroom, plus the following individual level variables: teachers' early expectations, and students' early perceived competence, gender, and age.

Firstly, passage from unconditional to base model (i.e., the addition of the predictors variables) entrains strong reductions in within and between groups variance. Actually, the deviance statistic of the model $(-2 \log L)$ strongly decreases $(\Delta=154.44$ for 5 degrees of freedom). This is a substantial and significant improvement in the fit statistic $(p<.001)$, meaning that the variables entered in the model significantly enhance the prediction of students' perceived competence. Moreover, results of this base model show that the teachers' expectations variable significantly predicted students' later perceived competence $(\beta=.16, p<.01)$, even after controlling for students' initial perceived competence, gender and age. This result means that teachers' early expectations of students' competence explained change in students' perceived competence.

Secondly, passage from base model to model 1 (i.e., the addition of the quadratic term) 
significantly improves the fit statistic of the model $(\Delta=3.93$ for 1 degree of freedom; $p<.05)$. This result indicates that the relation between teachers' expectations and students' perceived competence is best represented by a non-linear relationship; namely this relation varies depending on the valence of teachers' expectations (see Figure 1).

To further examine this curvilinear relation between teachers' expectations and students' perceived competence, standardized coefficients were calculated separately for high vs. low level of teachers' expectations. High and low levels were represented by scores of 1 standard deviation above and below the mean, respectively. Results indicate that TEE were stronger for high expectations $(\beta=.33, p<.01)$ than for low ones $(\beta=.06, p=\mathrm{ns})$.

\section{Does an autonomy-supportive climate moderates TEE?}

In order to examine whether the autonomy-supportive level of classroom climate moderate TEE, model 2 was tested (see data analyses section). Results (see Table 2; model 2) show that (1) the deviance statistic of the model strongly decreases $(\Delta=32.8$ for 4 degrees of freedom, $p<.05$ ), and (2) the product term (classroom autonomy-supportive climate $\times$ squared teacher expectations) significantly predicted students' final perceived competence $(p<.05)$. This means that TEE on students' perceived competence vary depending on the autonomy-supportive level of classroom motivational climate. Figure 2 represents slopes of the predicted relations separately for high and low levels of the moderator.

To further examine this interaction between teachers' expectations and autonomy-supportive climate, standardized coefficients were calculated separately for classrooms with high vs. low level of autonomy-supportive climate (high and low were represented by scores of 1 standard deviation above and below the mean, respectively). Results show that TEE were significant in low $(\beta=.32, p$ $<.01)$ but not in high autonomy-supportive climate $(\beta=-.04, p=n s)$. These results confirm our hypothesis that teachers' expectations predicted changes in students' perceived competence in classrooms where the teacher was perceived as hindering autonomy (i.e., controlling) more than classrooms where the teacher was perceived as supporting autonomy. It is interesting to note that 
this moderating effect of autonomy-supportive climate on TEE process seems particularly significant for students labeled with low expectations.

\section{Discussion}

The purposes of this longitudinal study were to examine, in a naturalistic physical education setting, (1) the relation between teachers' early expectations and students' later perceived competence, and (2) whether this relation varies as a function of the classroom autonomysupportive climate.

Teachers' early expectations and students' later perceived competence: A curvilinear relation?

First of all, our analyses confirm that teachers' expectations about students' future competence may be one environmental factor explaining changes in students' perceived competence. Actually, after controlling for some relevant background variables, teachers' early expectations predicted students' later perceived competence. This result is in agreement with prior naturalistic studies carried out in physical education (e.g., Trouilloud et al., 2002) and in other educational contexts (e.g., Jussim, 1989; Madon et al., 2001). It is important to note that this study is the first, to our knowledge, to use multilevel analysis to demonstrate TEE on students' perceived competence. The statistical requirements of this kind of analysis (notably integrating hierarchical design of the data and between-class differences) enhance the validity of the results. This effect is on average - relatively limited $(\beta=.15)$, but consistent with those of between .1 and .3 obtained in prior works under naturalistic conditions (see Jussim et al., 1998). Thus, students' perceived competence seems to be an important social-cognitive variable involved in the TEE process, since students might come to internalize teachers' expectations, with potential consequences for their self-esteem, motivation and achievement.

Multilevel analyses also indicated that TEE on students' perceived competence seem to be stronger when those expectations were positive $(\beta=.33)$. This tendency for high expectations to be more powerful than negative ones is consistent with some previous studies in other contexts, such as mathematics classrooms (Madon et al., 1997) and familial relations (Madon, Guyll, Spoth, Cross, 
\& Hilbert, 2003). Several theories may explain this result. According to self-enhancement theory (Sedikides, 1993), people are motivated to maintain a high level of self-esteem, and thus have a powerful desire for positive labels and feedback. Based on these propositions, one may think that students might have paid more attention and reacted more to positive expectations than to negative ones. Self-verification theory (Swann, Rentfrow, \& Guinn, 2002) may also partially explain this result. According to this theory, people want other to confirm (and thus stabilize) their own selfviews. Thus, because in this study students' perceived competence and teachers' expectations were relatively high ( $M=4.58$ and 4.68, respectively; see Table 1$)$, positive teachers' expectations might have been more powerful than negative ones because they were better matched with students' own self-views. It is interesting to notice that in Madon et al.'s (1997) study, students' perceived competence in the mathematics domain and teachers' expectations were also rather high $(M=10.22$ on a 1-14 scale and $M=3.49$ on a 1-5 scale, respectively). Consequently, additional studies are needed in domains where students' perceived competence and teachers' expectations are lower, to explore whether the differential power of high vs. low teachers' expectations is a robust pattern of results or whether it depends on some characteristics of the situation (e.g., subject classes).

\section{Autonomy-supportive climate as a moderator}

Because little is known about contextual moderators of TEE, this study was conduced to examine whether the size of this phenomenon varies depending on the classroom motivational climate created by the teacher. Based on some theoretical tenets of self-determination theory (Deci $\&$ Ryan, 2002), it was postulated that the autonomy-supportive nature of this motivational climate may moderate TEE process. The multilevel analyses yielded interesting support for this hypothesis. Specifically, the interaction between teachers' expectations and a classroom autonomy-supportive climate indicated that classrooms with low levels of an autonomy-supportive climate are more prone to generate TEE. By contrast, classrooms with high levels of an autonomy-supportive climate could buffer TEE and seem favorable for every student. More precisely, a low autonomy-supportive climate appeared to be particularly harmful to students labeled with low expectations. As seen in 
Figure 2, perceived competence of these students was weaker than the perceived competence of those associated with high expectations and/or evolving in a high autonomy-supportive climate.

Several explanations can be advanced for these results. Some deal with the teachers characteristics, others deal with the students.

On the student side.

One important way an autonomy-supportive climate may moderate the impact of TEE is by affecting students' motivational orientation. According to the diathesis-stress model (e.g., Boggiano, 1998; Guay, Boggiano, \& Vallerand, 2001), an autonomy-supportive climate may produce an intrinsic motivational orientation, which in turn may engender adaptive achievement patterns such as perceived competence and internal perceived locus of control. Autonomy-oriented individuals tend to perceive performance feedback as useful information rather than as a potentially ego-threatening indicator of self-worth (e.g., Koestner \& Zuckerman, 1994). Consequently, it is possible that autonomy-oriented students labeled with low expectations interpret teachers' expectations-related behaviors (e.g., evaluative feedback) as information that increased effort will be required to achieve successfully. Conversely, in a low autonomy-supportive climate, students may develop an extrinsic motivational orientation, and tend to regulate their behaviors according to pressures, contingencies, and perceived expectations. In this case, individuals are particularly sensitive to external factor (e.g., Neighbors \& Knee, 2003) like teachers' expectations, and less able to adopt self-initiated and regulated effort than are autonomy-oriented students. Thus, extrinsic students characterized by a fragile sense of effort-outcome dependence could interpret negative teachers' expectations-related behaviors (e.g., criticism) as an indication of their inability to attain the desired outcome through heightened effort, thereby fostering a feeling of incompetence. From this point of view, only those who received positive teachers' expectations-related behaviors (e.g., positive feedback, good marks) could maintain or develop a higher level of perceived competence. This explanation is also in line with Harter's (1999) model, which posits that extrinsically oriented children have a greater dependence on external approvals and goals, whereas intrinsically oriented 
children rely on a self-reward system and mastery goals.

\section{On the teacher side.}

Teachers' characteristics may also partially explain our results. One may think that the climate elaborated by teachers is related to their beliefs about the nature of students' ability. Researchers in school (e.g., Dweck, 1999) and in the physical ability area (e.g., Sarrazin et al., 1996) have identified two theories of intelligence or sport ability: (a) intelligence/sport ability as a global and stable entity, and (b) intelligence/sport ability as the incremental accumulation of skills and knowledge. Teachers who hold an entity theory should be less prone to organize an autonomysupportive climate because they would believe that students' general level cannot be easily altered. Consequently, they can treat high- and low-expectations students differently and unequally, paying more attention and teaching more material to high than to low students. As a result, teachers providing a low autonomy-supportive climate may be more prone to demonstrate cues about their expectations toward their students, and thus make TEE more significant (and particularly harmful to students associated with low expectations). In contrast, teachers subscribing to the incremental theory (i.e., believing that every student can improve) should be more prone to organize an autonomy-supportive climate and to treat students equally in their classrooms. Consequently, these teachers may less clearly express what they expect about their students, and thus make TEE weaker.

Because these explanations (whether for student or teacher characteristics) are hypothetical, further studies are needed to explore the role played by students' motivational orientation and/or teachers' beliefs about the nature of ability in the TEE process.

\section{Limitations}

Although the present results provide some support for the moderating role of a classroom autonomy-supportive climate in TEE process, some limitations should be taken into consideration when interpreting these findings.

First of all, the data for this research came from a naturalistic rather than an experimental design. Even though a longitudinal procedure was used, the correlational design of this study may 
limits the ability to draw strong causal inferences. Consequently, whether observed relationships between teachers' expectations and students' perceived competence are caused by teachers' expectations cannot ultimately be determined within the context of this study. For this reason, experimental research (as well as longitudinal studies over several years) may provide a clearer picture about moderators of TEE. Although the design of this study may have some limitations, it also has some strengths such as the ecological validity of the data, the temporal order in which the data were collected, the consideration for the multilevel structure of data, the controls for prior differences between students, and the theoretically consistent findings. For instance, entering students' data were collected prior to teachers' expectations, which, in turn, were collected prior to ending students' data. This procedure reduces ambiguity in determining the order of relations and rules out some causal explanations. Moreover, the findings from this study are consistent with experimental studies (see Snyder \& Stukas, 1999, for a review) in which strong causal inferences have been drawn. Finally, the methods used in this study were consistent with those of other published naturalistic studies on interpersonal expectations effects (e.g., Jussim, 1989; Kuklinski \& Weinstein, 2001; Madon et al., 2003; Trouilloud et al., 2002). This helps to identify the contributions of the present research to existing works on naturally occurring TEE.

Another limitation involves the omitted variable problem (Judd \& McClelland, 1989), that is, the possibility that a relevant predictor was omitted from the analyses. Although longitudinal designs do rule out the possibility that the outcome caused changes in the predictors, they do not rule out the possibility that a third, unmeasured variable was responsible for changes in both the predictor and the outcome. If students' perceived competence was predicted by other variables that were not controlled for statistically, then TEE were smaller than reported. Consequently, other elements such as parents' and peers' expectations may affect students' perceptions of competence and need to be assessed in further works.

Finally, because classroom motivational climate was assessed during the school year (notably after teachers' expectations), there was a possibility that this climate was partially a result 
of TEE. Indeed, the motivational climate instituted by the teacher might be influenced by what teachers expected their students to do. Nevertheless, because the zero-order correlation between teachers' expectations and perceived motivational climate is null $(r=.02, p=n s$; see Table 1$)$, it is unlikely that, in this study, classroom motivational climate was determined by teachers' expectations.

\section{Conclusion}

Research on teachers' expectations for the last 30 years has represented an active area of theoretical and methodological debate. Despite the limitations mentioned above, we believe that the present findings highlight some interesting elements for the comprehension of interpersonal expectations effects in the educational domain. Actually, most prior studies emphasize significant but modest TEE on average. Because TEE represents a probabilistic phenomenon (Babad, 1993), discovering characteristics of people and situations more likely to generate expectations effects not only enriches theoretical knowledge, but permits identification of appropriate candidates for potential intervention. On this point, results of this study confirm that, even if average TEE on students' perceived competence are relatively modest, some factors may increase (or decrease) it. Specifically, multilevel analysis provided naturalistic evidence that the level of teachers' expectations and motivational climate established by teachers at the classroom level can moderate the relation between teachers' early expectations and students' later perceived competence. Despite their relative weakness (in terms of standardized coefficients), these results should not be misinterpreted as trivial or unimportant. Importance and effect size are not identical issues. Some researchers (e.g., Aguinis \& Stone-Romero, 1997) have explained that naturalistic designs may generate several artifacts (e.g., measurement error, multicollinearity, low residual variance of the product term in the equation, residual variance heterogeneity, unequal sample size across moderator variable-based subgroups) likely to bias moderator effects downwardly. That is why when moderator effects are found in naturalistic studies, the reduction in model error due to adding the product term is often disconcertingly low, about 1 to $3 \%$ of the variance (McClelland \& Judd, 
1993). Moreover, relatively small TEE can be quite important for students, notably if the same students were affected by those expectations effects over the years (and over multiple teachers). Actually, if every year one set of students were the beneficiaries of positive expectations effects and another set were victims of negative expectations effects, huge self-fulfilling effects could occur over several years (Smith, Jussim, \& Eccles, 1999). Thus, because of their relevance to social issues (such as contribution to inequality between students), and theoretical issues (such as the construction of social reality), such effects are quite important.

\section{TEE and self-determination theory}

By integrating some propositions from self-determination theory (Deci \& Ryan, 2002) in the TEE process, the current study presents some contributions for the comprehension of this phenomenon. Indeed, results of our analyses highlight the importance of an autonomy-supportive climate as a basic functional dimension useful in understanding the impact of teachers' expectations (and interpersonal motivating style) on students' outcomes. Specifically, the effects of classroom motivational climate on students' perceived competence came in two forms - as a main effect and as a moderator of TEE. As a main effect, a shared autonomy-supportive climate predicted students' perceived competence $(\beta=.37$; see model 2, Table 2), confirming earlier works (e.g., Deci et al., 1991; Reeve, 2002) showing that students in classrooms with autonomy-supportive teachers displayed higher perceived competence than did students in classrooms with controlling teachers ${ }^{5}$. But beyond that, classroom autonomy-supportive climate seems to moderate the relation between teachers' early expectations and students' later perceived competence. This result suggests that TEE tend to be stronger in low autonomy support climates. Thus, self-determination theory tenets may partially explain why TEE may be stronger in some contexts and for some individuals. From a research perspective, future works concerned with the comprehension of TEE process may attempt to more fully articulate TEE and self-determination theory tenets. For example, it would be interesting to explore (1) whether teachers' expectations - beyond their influence on students' perceived competence - impact students' level of self-determination and/or their achievement, and 
(2) whether this whole process is moderated by the autonomy-supportive level of the classroom climate.

This interaction between teachers' expectations and classroom motivational climate is not solely of theoretical importance. It has practical importance as well. From an applied perspective, the findings provide some insight into how physical education teachers may avoid negative consequences of TEE processes. Specifically, the data suggest that teachers should seek to promote a classroom climate oriented toward autonomy-support, because this dimension seems to reduce the negative impact of interpersonal expectations.

\section{TEE and multilevel analysis}

Finally, we would like to highlight the importance of using multilevel analysis in studies on TEE. Because nearly all data collected in TEE studies have a hierarchical structure, multilevel modeling should always be the statistical technique of choice for these kinds of studies. This approach provides a richer and more appropriate methodological design for evaluating TEE processes than would be possible with traditional single-level approaches that ignore the clustering of students in classrooms. Particularly when the focus of the research is on an inherently classroomlevel variable such as "climate", it makes no sense to ignore the classroom level in the analysis. Moreover, because knowledge about conditions under which such effects are particularly strong is still weak, the quest for moderators of naturally TEE needs to be extended. On this point, multilevel approaches allow researchers to integrate some teacher (e.g., background, implicit theories) and classroom (e.g., size, average-level) characteristics in order to further identify contextual or individual characteristics that set into motion psychological processes that undermine TEE for some students and not for others. 


\section{References}

Aguinis, H., \& Stone-Romero, E. F. (1997). Methodological artifacts in moderated multiple regression and their effects on statistical power. Journal of Applied Psychology, 82, 192-206.

Ames, C. (1992). Classrooms: Goals, structures, and student motivation. Journal of Educational Psychology, 84, 261-271.

Atkinson, J. W. (1964). An introduction to motivation. Oxford, England: Van Nostrand.

Babad, E. Y. (1993). Pygmalion - 25 years after interpersonal expectations in the classroom. In P. D. Blanck (Ed.), Interpersonal expectations: Theory, research, and application (pp.125-153). London: Cambridge University Press.

Babad, E. Y. (1998). Preferential affect: The crux of the teacher expectancy issue. Advances in Research on Teaching, 7, 183-214.

Babad, E. Y., Inbar, J., \& Rosenthal, R. (1982). Pygmalion, Galatea, and the Golem: Investigations of biased and unbiased teachers. Journal of Educational Psychology, 74, 459-474.

Bandura, A. (1997). Self-efficacy: the exercise of control. New York, Freeman.

Baron, R., \& Kenny, D. (1986). The moderator-mediator variable distinction in social psychological research: Conceptual, strategic, and statistical considerations. Journal of Personality and Social Psychology, 51, 1173-1182.

Black, A. E., \& Deci, E. L. (2000). The effects of instructors' autonomy support and students' autonomous motivation on learning organic chemistry: A self-determination theory perspective. Science Education, 84, 740-756.

Blanck, P. (1993). Interpersonal expectations: Theory, research, and application. London: Cambridge University Press.

Boggiano, A. K. (1998). Maladaptive achievement patterns : A test of a diathesis-stress analysis of helplessness. Journal of Personality and Social Psychology, 51, 1173-1182.

Bong, M., \& Skaalvik, E. M. (2003). Academic self-concept and self-efficacy: How different are they really ? Educational Psychology Review, 15, 1-40. 
Brattesani, K. A., Weinstein, R. S., \& Marshall, H. H. (1984). Student perceptions of differential teacher treatment as moderators of teacher expectation effects. Journal of Educational Psychology, 76, 236-247.

Brophy, J. (1983). Research on the self-fulfilling prophecy and teacher expectations. Journal of Educational Psychology, 75 (5), 631-661.

Brophy, J. \& Good, T. (1974). Teacher-student relationships: Causes and consequences. New York: Holt, Rinehart \& Winston.

Bryk, A. S., \& Raudenbush, S. W. (1992). Hierarchical linear models: Applications and data analysis methods. Newbury Park, Sage.

Church, M. A., Elliot, A. J., \& Gable, S. L. (2001). Perceptions of classroom environment, achievement goals, and achievement outcomes. Journal of Educational Psychology, 93, 43-54.

Cohen, A., Doveh, E., \& Eick, U. (2001). Statistical properties of the $r_{\mathrm{wg}(\mathrm{i})}$ index of agreement. Psychological Methods, 6, 297-310.

Cooper, H. M. (1979). Pygmalion grows up: A model of teacher expectation communication and performance influence. Review of Educational Research, 49, 389-410.

Cooper, H. M., \& Good, T. (1983). Pygmalion grows up: Studies in the expectation communication process. New York: Longman.

Cooper, H. M., \& Hazelrigg, P. (1988). Personality moderators of interpersonal expectancy effects: An integrative research review. Journal of Personality and Social Psychology, 6, 937-949.

Darley, J. M., \& Fazio, R. H. (1980). Expectancy-confirmation processes arising in the social interaction sequence. American Psychologist, 35, 867-881.

Deci, E. L., \& Ryan, R. M. (2000). The "what" and the "why" of goals pursuits: Human needs and the self-determination of behaviour. Psychological Inquiry, 11, 227-268.

Deci, E. L., \& Ryan, R. M. (2002). Handbook of self-determination. Rochester, New York : University of Rochester Press.

Deci, E. L., Vallerand, R. J., Pelletier, L. G., \& Ryan, R. M. (1991). Motivation and education: The 
self-determination perspective. Educational Psychologist, 26, 325-346.

DeJong, R., \& Westerhof, K. J. (2001). The quality of student ratings of teacher behaviour, Learning Environments Research, 4, 51-85.

Duda, J., Nicholls, J. (1992). Dimensions of achievement motivation in schoolwork and sport. Journal of Educational Psychology, 84, 1-10.

Dweck, C. S. (1999). Self-Theories: Their role in motivation, personality, and development. Philadelphia. Taylor \& Francis.

Eccles, J. S., \& Wigfield, A. (1985). Teacher expectations and student motivation. In J. Dusek (Eds.), Teacher expectancies. Hillsdale, NJ: Erlbaum.

Eccles, J. S., \& Wigfield, A. (2002). Motivational beliefs, values, and goals. Anmual Review of Psychology, 53, 109-132.

Eder, D. (1981). Ability grouping as a self-fulfilling prophecy: A micro-analysis of teacher-student interaction. Sociology of Education, 54, 151-161.

Finn, J. (1972). Expectations and the educational environment. Review of Educational Research, 42, $387-410$.

Good, T. L. (1987). Two decades of research on teacher expectations: Findings and future directions, Journal of Teacher Education,38, 32-47.

Good, T. L., \& Brophy, J. E. (2000). Looking in classrooms ( $8^{\text {th }}$ ed.). New York: Longman.

Good, T. L., \& Nichols, S. L. (2001). Expectancy effects in the classroom: A special focus on improving the reading performance of minority students in first-grade classrooms. Educational Psychologist, 36 (2), 113-126.

Good, T. L., \& Thompson, E. K. (1998). Research on the communication of performance expectations: A review of recent perspectives. Advances in Research on Teaching, 7, 273-308.

Guay, F., Boggiano, A. K., \& Vallerand, R. J. (2001). Autonomy support, intrinsic motivation, and perceived competence: Conceptual and empirical linkages. Personality and Social Psychology Bulletin, 27, 643-650. 
Harris, M. J. (1989). Personality moderators of interpersonal expectancy effects: replication of Harris and Rosenthal (1986). Journal of Research in Personality, 23, 381-397.

Harris, M. J. \& Rosenthal, R. (1985). Mediation of interpersonal expectancy effects: 31 metaanalyses. Psychological Bulletin, 97, 363-386.

Harter, S. (1999). The construction of the self: A developmental perspective. New York, US: Guilford Press.

Hazelrigg, P. J., Cooper, H., \& Strathman, A. J. (1991). Personality moderators of the experimenter expectancy effect: A reexamination of five hypotheses. Personality and Social Psychology Bulletin, 17, 569-579.

Horn, T. S. (2003). Developmental perspectives on self-perceptions in children and adolescents. In M. R. Weiss (Ed.), Developmental sport and exercise psychology: A lifespan perspective (pp. 101-143). Morgantown, WV: Fitness Information Technology.

James, L. R., Demaree, R. G., \& Wolf, G. (1993). $r_{w g}$ : An assessment of within group interrater agreement. Journal of Applied Psychology, 78, 306-309.

Judd, C. M., \& McClelland, G. H. (1989). Data analysis: A model-comparison approach. Orlando, FL: Harcourt Brace Jovanovitch.

Jussim, L. (1986). Self-fulfilling prophecies: A theoretical and integrative review. Psychological Review, 93, 429-445.

Jussim, L. (1989). Teacher expectations: Self-fulfilling prophecies, perceptual biases, and accuracy. Journal of Personality and Social Psychology, 57, 469-480.

Jussim, L. \& Eccles, J. S. (1992). Teacher expectations 2: Construction and reflection of student achievement. Journal of Personality and Social Psychology, 63, 947-961.

Jussim, L., Eccles, J. S., \& Madon, S. (1996). Social perception, social stereotypes and teacher perceptions: Accuracy and the search for the powerful self-fulfilling prophecy. Advances in Experimental Social Psychology, 28, 281-388.

Jussim, L., \& Harber, K. D. (2005). Teacher expectations and self-fulfilling prophecies: Knows and 
unknowns, resolved and unresolved controversies. Personality and Social Psychology Review, 9, 131-155.

Kenny, D. A., Kashy, D. A., \& Bolger, N. (1998). Data analysis in social psychology. In D. T. Gilbert, S. T. Fiske, \& G. Lindsey (Eds.), The handbook of social psychology (4 ${ }^{\text {th }}$ ed., Vol. 1, pp. 233-265) New York: McGraw-Hill.

Koestner, R., \& Zuckerman, M. (1994). Causality orientations, failure, and achievement. Journal of Personality, 62, 321-346.

Kuklinski, M. R., \& Weinstein, R. S. (2001). Classroom and developmental differences in a path model of teacher expectancy effects. Child Development, 72 (5), 1554-1578.

McClelland, G. H., \& Judd, C. M. (1993). Statistical difficulties of detecting interactions and moderator effects. Psychological Bulletin, 114, 376-390.

McKown, C., \& Weinstein, R. S. (2002). Modeling the role of child ethnicity and gender in children's differential response to teacher expectations. Journal of Applied Social Psychology, $32,159-184$.

Madon, S., Guyll, M., Spoth, R. L., Cross, S. E., \& Hilbert, S. J. (2003). The self-fulfilling influence of mother expectations on children's underage drinking. Journal of Personality and Social Psychology, 84, 1188-1205.

Madon, S., Jussim, L., \& Eccles, J. S. (1997). In search of the powerful self-fulfilling prophecy. Journal of Personality and Social Psychology, 72, 791-809.

Madon S., Smith A., Jussim L., Russell D. W., Walkiewicz M., Eccles J. S., \& Palumbo P. (2001). Am I as you see me or do you see me as I am? Self-fulfilling prophecies and self-verification. Personality and Social Psychology Bulletin, 27, 1214-1224.

Miller, D. T., \& Turnbull, W. (1986). Expectancies and interpersonal processes. Anmual Review of Psychology, 37, 233-256.

Neighbors, C., \& Knee, R. (2003). Self-determination and the consequences of social comparison. Journal of Research in Personality, 37, 529-546. 
Nicholls, J. G. (1989). The competitive ethos and democratic education. MA: Harvard University Press. Cambridge.

Nicholls J. G., Cheung P., Lauer J., Patashnick M. (1989). Individual differences in academic motivation: Perceived ability, goals, beliefs, and values. Learning and Individual Differences, $1,63-84$

Olson, J. M., Roese, N. J., \& Zanna, M. P. (1996). Expectancies. In E. T. Higgins, \& A. W. Kruglanski (Eds.), Social Psychology: Handbook of basic principles (pp. 211-238). New York: Guilford Press.

Pajares, F., \& Schunk, D. H. (2002). Self and self-belief in psychology and education: An historical perspective. In J. Aronson \& D. Cordova (Eds.), Psychology of education: Personal and interpersonal forces (pp. 5-25). New York: Academic Press.

Papaiannou, A., Marsh, H. W, \& Theodorakis, Y. (2004). A multilevel approach to motivational climate in physical education and sport settings: An individual or a group level construct? Journal of Sport and Exercise Psychology, 26, 90-118.

Parsons, J. E., Kaczala, C. M., Meece, J. L. (1982). Socialization of achievement attitudes and beliefs: Classroom influences. Child Development, 53, 322-339.

Patrick, H., Anderman, L. H., \& Ryan, A. (2002). Social motivation and the classroom social environment. In C. Midgley (Ed), Goals, goal structures, and patterns of adaptive learning (pp. 85-108). Mahwah, NJ, US: Lawrence Erlbaum Associates, Publishers.

Pelletier, L. G., \& Vallerand, R. J. (1996). Supervisors' beliefs and subordinates' intrinsic motivation: A behavioral confirmation analysis. Journal of Personality and Social Psychology, $71,331-340$.

Pintrich, P. R., \& Shunk, D. H. (1996). Motivation in education: Theory, research, and applications. Englewwod Cliffs, NJ: Merril1/Prentice Hall.

Rasbash, J., Browne, W., Goldstein, H., Yang, M., Plewis, I., Woodhouse, G., Draper, D., 
Langford, I., \& Lewis, T. (2000). A user's guide to Mlwin. London: Institute of Education, University of London.

Raudenbush, S. W. (1984). Magnitude of teacher expectancy effects on pupil IQ as a function of the credibility of expectancy induction: A synthesis of findings from 18 experiments. Journal of Educational Psychology, 76, 85-97.

Reeve, J. (2002). Self-determination theory applied to educational settings. In E. L. Deci \& R. M. Ryan (Eds.), Handbook of self-determination research (pp. 184-203). Rochester: University of Rochester Press.

Reeve, J., Bolt, E., \&, Cai, Y. (1999). Autonomy-supportive teachers: How they teach and motivate students. Journal of Educational Psychology, 91, 537-548.

Robinson, W. S. (1950). Ecological correlations and the behaviors of individuals. American Sociological Review, 15, 351-357.

Rosenthal, R. (1974). On the social psychology of the self-fulfilling prophecy: Further evidence for Pygmalion effects and their mediating mechanisms. New York: MSS Modular Publications.

Sarrazin, P., Biddle, S., Famose, J. P., Cury, F., Fox, K., \& Durand, M. (1996). Goal orientations and conceptions of the nature of sport ability in children: A social cognitive approach. British Journal of Social Psychology, 35, 399-414.

Sarrazin, P., Roberts, G., Cury, F., Biddle, S., \& Famose, J.-P. (2002). Exerted effort and performance in climbing among boys: The influence of achievement goals, perceived ability, and task difficulty. Research Quarterly for Exercise and Sport, 73, 425-436.

Sedikides, C. (1993). Assessment, enhancement, and verification determinants of the selfevaluation process. Journal of Personality and Social Psychology, 65, 317-338.

Skinner, E. A. (1995). Perceived control, motivation, and coping. Thousand Oaks, CA, US: Sage Publications.

Smith, A. E., Jussim, L., \& Eccles, J. (1998). Self-fulfilling prophecies, perceptual biases, and accuracy at the individual and group levels. Journal of Experimental Social Psychology, 34, 
$530-561$.

Smith, A. E., Jussim, L., \& Eccles, J. (1999). Do self-fulfilling prophecies accumulate, dissipate, or remain stable over time? Journal of Personality and Social Psychology, 77, 548-565.

Snyder, M., Stukas Jr A. A. (1999). Interpersonal processes: The interplay of cognitive, motivational, and behavioral activities in social interaction. Anmual Review Of Psychology, 50, 273-303.

Stipek, D. J. (2002). Motivation to learn: Integrating theory and practice. Boston: Allyn \& Bacon.

Sutherland, A., \& Goldschmid, M. L. (1974). Negative teacher expectation and IQ change in children with superior intellectual potential. Child Development, 45, 852-856.

Swann, W. B., \& Ely R. J. (1984). A battle of wills: Self-verification versus behavioral confirmation. Journal of Personality and Social Psychology, 46, 1287-1302.

Swann, W. B., Rentfrow, P. J., \& Guinn, J. (2002). Self-verification: The search for coherence. In M. Leary and J. Tagney, Handbook of self and identity: Guilford, New York.

Trouilloud, D., \& Sarrazin, P. (2003). Les connaissances actuelles sur 1'effet Pygmalion: Processus, poids et modulateurs. Revue Française de Pédagogie, 145, 89-119.

Trouilloud D., Sarrazin P., Martinek, T., \& Guillet, E. (2002). The influence of teacher expectations on students achievement in physical education classes: Pygmalion revisited. European Journal of Social Psychology, 32, 591-607.

Urdan T. (2001). Contextual influences on motivation and performance: An examination of achievement goals structures. In F. Salili, \& C. Chiu (Eds.), Student motivation: The culture and context of learning (pp. 171-201). Dordrecht, Netherlands: Kluwer Academic Publishers.

Weinstein, R. S., \& McKown, C. (1998). Expectancy effects in "context": Listening to the voices of students and teachers. Advances in Research on Teaching, 7, 215-242.

Weinstein, R. S., Marshall, H. H., Botkin, M., \& Sharp, L. (1987). Pygmalion and the student: Age and classroom differences in children's awareness of teacher expectations. Child Development, 58, 1079-1093. 
Wigfield, A., \& Eccles, J. S. (2000). Expectancy-value theory of achievement motivation.

Contemporary Educational Psychology, 25, 68-81. 
Author Note

The authors would like to thank Luc Pelletier for his suggestions and helpful feedback on this article. We would also like to acknowledge CarolAnne M. Kardash and the three anonymous reviewers for their insightful comments on earlier versions of the manuscript. 


\section{Footnotes}

${ }^{1}$ Within the academic research literature, a variety of terms have been used to describe particular aspects of individuals' perceptions of the self. These terms include perceived competence (Deci \& Ryan, 2000; Harter, 1999), perceived ability (Nicholls, 1989), self-efficacy (Bandura, 1997), probability of success (Atkinson, 1964), etc. Despite some relatively minor differences, there has been general consistency in the definitions of these constructs (see Horn, 2003). In this paper, the term perceived competence referred to individuals' perceptions of their competencies or ability in specific domains (e.g., physical education settings) (see Harter, 1999).

${ }^{2}$ In the literature, the notion that teachers' expectations about students will transform their behaviors in ways that confirm the initial expectations is also called self-fulfilling prophecy (Brophy, 1983 ; Jussim, 1986) or Pygmalion effect (Rosenthal, 1974).

${ }^{3}$ This is mainly because students in the same classroom come from the same recruiting area, have common social characteristics, share a common destiny, and interact with each other.

${ }^{4}$ The major focus of the present study was on classroom climate, and so autonomy-supportive climate was represented as a class-level variable (i.e., the mean of the individuals' perceptions). Nevertheless, when each student evaluates his/her perception of the classroom climate, it seems pertinent (and interesting) to consider responses at both the individual and the classroom level (see Papaioannou et al., 2004). Consequently, and because multilevel modeling framework permits to include appropriately both the individual-level and class-level representations, autonomy-supportive climate was integrated in our models at level 2 (classroom) and at level 1 (student).

${ }^{5}$ We can notice that autonomy-supportive climate at the individual-level also predicted students' later perceived competence $(\beta=.16$; see Table 1 , model 2 ). Thus, autonomy-supportive climate may operate in two ways: beyond the role played by autonomy-supportive climate at the classroom level $(\beta=.37)$, the individual perceptions of autonomy-supportive climate (i.e., the extent to which individual student perceptions differed from those of the class-average) contributed to changes in students' perceived competence. This result illustrates the relevance of multilevel modeling 
approach by evaluating the simultaneous effects of motivational climate at both classroom and individual level. 
Table 1

Descriptive statistics and correlations among individual-level variables

\begin{tabular}{|c|c|c|c|c|c|c|c|c|}
\hline Variables & Min-max & Mean & $\mathrm{SD}$ & 1 & 2 & 3 & 4 & 5 \\
\hline \multicolumn{9}{|l|}{ Student } \\
\hline 1. gender ${ }^{\mathrm{a}}$ & - & - & - & - & & & & \\
\hline 2. age & $11-18$ & 13.42 & 1.73 & .00 & - & & & \\
\hline $\begin{array}{l}\text { 3. initial perceived } \\
\text { competence }\end{array}$ & $1-7$ & 4.58 & 1.47 & $.25 * * *$ & $-.17 * *$ & - & & \\
\hline $\begin{array}{l}\text { 4. final perceived } \\
\text { competence }\end{array}$ & $1-7$ & 4.55 & 1.39 & $.15^{* *}$ & $-.24 * * *$ & $.54 * * *$ & - & \\
\hline $\begin{array}{l}\text { 5. perceived autonomy- } \\
\text { supportive climate }\end{array}$ & $1-7$ & 3.24 & 1.42 & .09 & .04 & $.11 *$ & $.22 * * *$ & - \\
\hline \multicolumn{9}{|l|}{ Teacher } \\
\hline $\begin{array}{l}\text { 6. teacher expectations of } \\
\text { student competence }\end{array}$ & $1-7$ & 4.68 & 1.32 & $.27 * * *$ & .02 & $.31 * * *$ & $.30 * * *$ & .02 \\
\hline
\end{tabular}

Note: $N=421 . * p<.05 . * * p<.01 . * * * p<.001$.

${ }^{\text {a }}$ girls were coded as 1 and boys were coded as 2 . 
Table 2

Results of the multilevel models for prediction of students' final perceived competence

\begin{tabular}{|c|c|c|c|c|c|c|c|}
\hline \multirow[t]{2}{*}{ Variables } & \multirow{2}{*}{$\begin{array}{c}\text { Empty model } \\
\text { Estimates }\end{array}$} & \multicolumn{2}{|c|}{ Base model } & \multicolumn{2}{|c|}{ Model 1} & \multicolumn{2}{|c|}{ Model 2 (full model) } \\
\hline & & Estimates & $\beta$ & Estimates & $\beta$ & Estimates & $\beta$ \\
\hline \multicolumn{8}{|l|}{ Fixed effects } \\
\hline Intercept & $4.534(0.118) * * *$ & $3.350(0,605) * * *$ & & 4.377 & & $-10.564(4.514)$ & \\
\hline Teacher expectations & & $0.171(0.045) * * *$ & .16 & $-0.304(0.243)$ & & $5.665(2.156) * *$ & \\
\hline Student initial perceived competence & & $0.431(0.041) * * *$ & .46 & $0.429(0.041) * * *$ & .45 & $0.421(0.039) * * *$ & .44 \\
\hline Gender & & $-0.002(0.117)$ & .00 & $0.028(0.117)$ & .01 & $0.064(0.113)$ & .02 \\
\hline Age & & $-0.117(0.039) * * *$ & -.15 & $-0.124(0.038) * *$ & -.16 & $-0.147(0.034) * * *$ & -.18 \\
\hline Individual autonomy-supportive climate & & & & & & $0.164(0.039) * * *$ & .16 \\
\hline Classroom autonomy-supportive climate & & & & & & $4.570(1.380) * * *$ & .37 \\
\hline Teacher expectations $\times$ Teacher expectations & & & & $0.054(0.027) *$ & & $-0.532(0.246) *$ & \\
\hline $\begin{array}{l}\text { Teacher expectations } \times \text { Classroom autonomy- } \\
\text { supportive climate }\end{array}$ & & & & & & $-1.851(0.663) * *$ & \\
\hline $\begin{array}{l}\text { Teacher expectations } \times \text { Teacher expectations } \times \\
\text { Classroom autonomy-supportive climate }\end{array}$ & & & & & & $0.182(0.076) *$ & \\
\hline
\end{tabular}

Random effects

Classroom level variance

\begin{tabular}{|c|c|c|c|}
\hline Intercept & $0.213(0.093) *$ & $0.041(0,032)$ & $0.039(0.032)$ \\
\hline
\end{tabular}

\begin{tabular}{|c|c|c|c|c|}
\hline Student level variance & $1.732(0.123) * * *$ & $1.246(0.088) * * *$ & $1.235(0.087) * * *$ & $1.159(0.082) * * *$ \\
\hline$-2 \log L$ & 1452.494 & 1298.053 & 1294.122 & 1261.323 \\
\hline
\end{tabular}

Note: $\mathrm{N}=421 . * p<.05 \quad * * p<.01 \quad * * * p<.001$

Standard errors are in parentheses. 
Figure Captions

Figure 1. Curvilinear relation between teachers' early expectations and students' later perceived competence

Figure 2. Plot of the moderating effect of classroom autonomy supportive climate on the relation between teachers' expectations and students' perceived competence. 


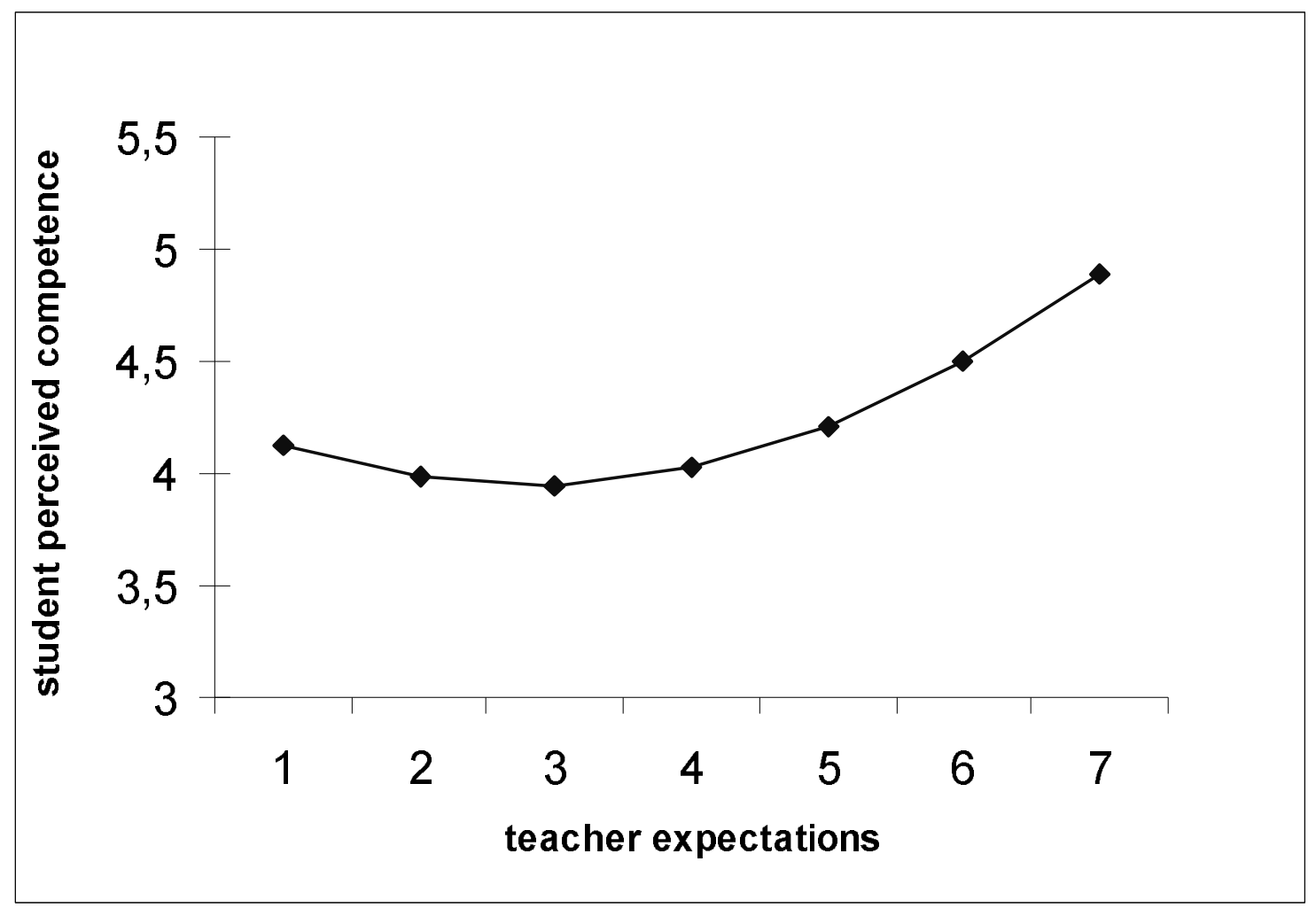




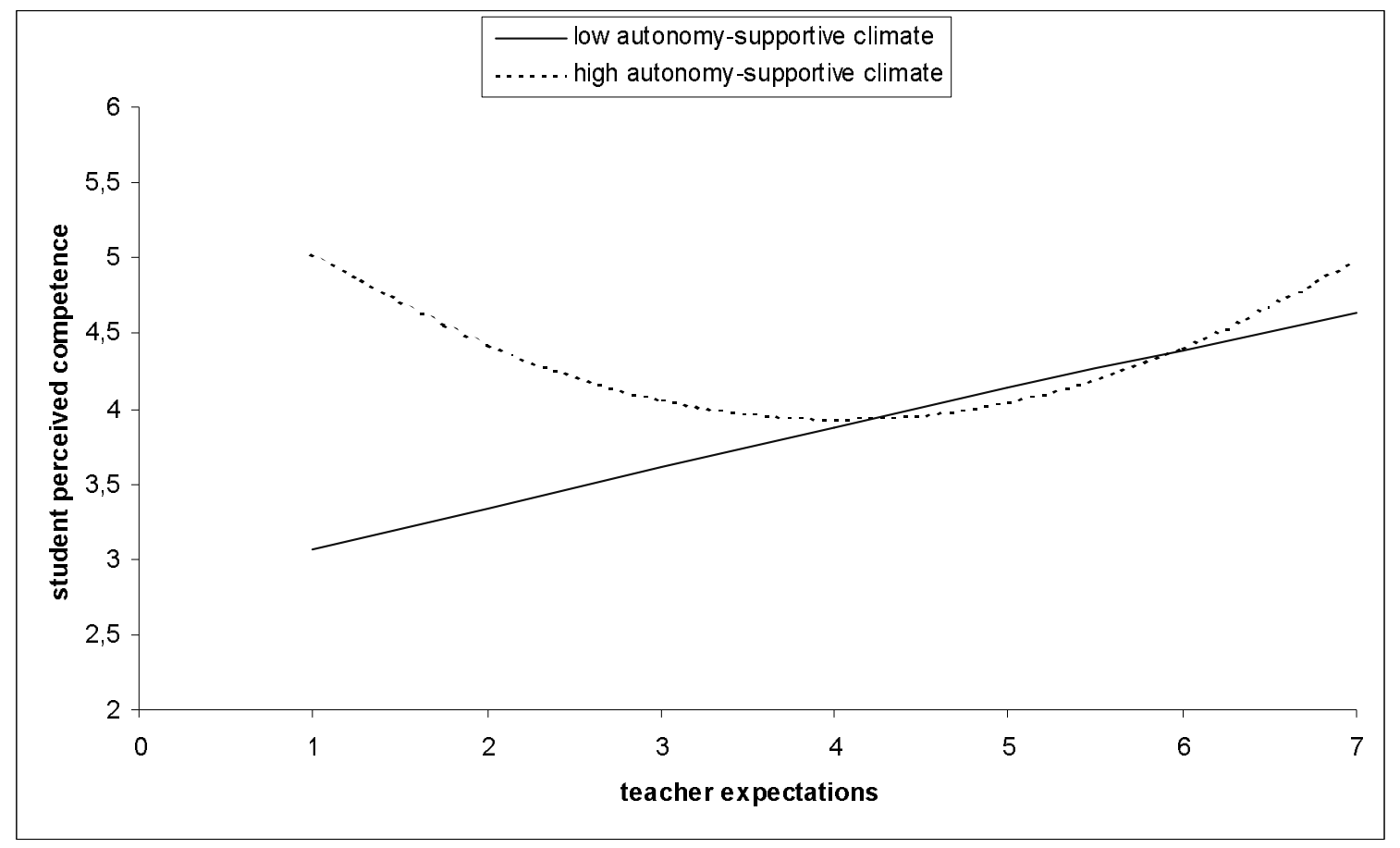


